\title{
Complexity in the recurrence of large earthquakes in southwestern Japan: A simulation with an interacting fault system model
}

\author{
Manabu Hashimoto \\ RCEP, Disaster Prevention Research Institute, Kyoto University, Gokasho, Uji, Kyoto 611-0011, Japan
}

(Received September 1, 1999; Revised May 18, 2000; Accepted May 30, 2000)

\begin{abstract}
Activity of large earthquakes in southwestern Japan is simulated with a model that incorporates mechanical interactions between faults, including both interplate and intraplate faults. In this simulation, each fault element is assumed to accumulate stress with a constant slip deficit rate and redistribute its accumulated stress to surrounding faults by making a forward (coseismic) slip when the cumulative stress reaches an assumed threshold. The results from the inversion of geodetic data by Hashimoto and Jackson (1993) were used to specify slip deficit rates for these faults. Each fault in this model is divided into four equal-sized elements, two in the length direction and two in the width direction, so that this model can simulate events as small as M6. A complex pattern of seismicity arises from a 10,000-year run of the simulation. The rate of stress accumulation is not necessarily constant for all faults, which may be attributed to the interaction between faults. It is interesting that fluctuations in the amplitude of stress changes with periods of 1,500 years or longer are seen for some inland faults. A variety of sizes of events occur according to the number of simultaneously rupturing elements. Smaller events in which only one element on a fault ruptures frequently occur, but large events with three or more rupturing elements are rarely seen. This implies that the difference between geodetic and geological/seismological strain rates might be made up by smaller events. Simulations indicate that two models with 1 initial conditions may separate by a factor of about $20 \sim 30$ in the state space after hundreds of years. The increase of this distance in the state space slows down or is linear in tome depending on initial conditions.
\end{abstract}

\section{Introduction}

Recently the Earthquake Research Committee, the Headquarters of Earthquake Research Promotion of the Japanese government, released evaluations of long-term activity of faults (Headquarters for Earthquake Research Promotion, 1997a, b, 1998), on the basis of geological studies, especially trench excavation studies, and "staircase" models for earthquake recurrence (Matsuda, 1977). These evaluations only imply possibilities of occurrence of large events on a specified fault system during next several hundred years. They are too vague to be utilized for practical purposes, such as city planning and land use, because the time span of these projects usually range from ten to fifty years. Therefore, the development of a forecasting method is needed, which is aimed at these time ranges and can incorporate new accurate data obtained by seismological and geodetic methods.

The "staircase" model of earthquake recurrence, adopted in the above evaluations, assumes that events with the same amount of slip recur periodically at a specified point on a fault. This model also implicitly assumes that the loading rate, fault strength, and stress drop are constant. However, this model ignores effects from other faults in the vicinity. Recent studies on coseismic stress changes show that the slip of a fault affects seismicity in its surrounding area (e.g. Hudnut et al., 1989; Harris and Simpson, 1992; Jaumè and

Copy right $(\mathrm{C}$ The Society of Geomagnetism and Earth, Planetary and Space Sciences (SGEPSS); The Seismological Society of Japan; The Volcanological Society of Japan; The Geodetic Society of Japan; The Japanese Society for Planetary Sciences.
Sykes, 1992; King et al., 1994; Hashimoto, 1995, 1997). Therefore it is worthwhile to evaluate quantitatively the effect of faulting in the surrounding region on the recurrence behavior of slip at a specified fault and to examine the extent that this assumption can be valid.

Since Burridge and Knoppoff (1967), theoretical models to simulate seismicity has been studied mainly with block sliders in which a block on the frictional surface is loaded through a spring connected to the block. With this model, Carlson and Langer (1989), Ito and Matsuzaki (1989), and others reached the idea of self-organized criticality that was first derived from sand pile models (Bak and Tang, 1989). Huang and Turcotte (1990) and Ruff (1992) also showed a complexity of modeled seismicity with two blocks connected to each other with an additional spring. However these models assume a regular distribution of blocks and a constant spring stiffness that gives a symmetrical interaction between the blocks. Actual faults are rather irregularly distributed, which implies asymmetrical interactions between faults. Rundle (1988a) developed a method to deal with such an interaction between real fault systems and applied his method to the fault system in southern California (Rundle, 1988b). Ward (1991) developed a synthetic seismicity model on the basis of a two-dimensional dislocation theory and applied it to the Middle America Trench. Ward (1996) also made a similar study with his two-dimensional plane stress model incorporating much more details of the fault system in southern California than Rundle (1988b). 

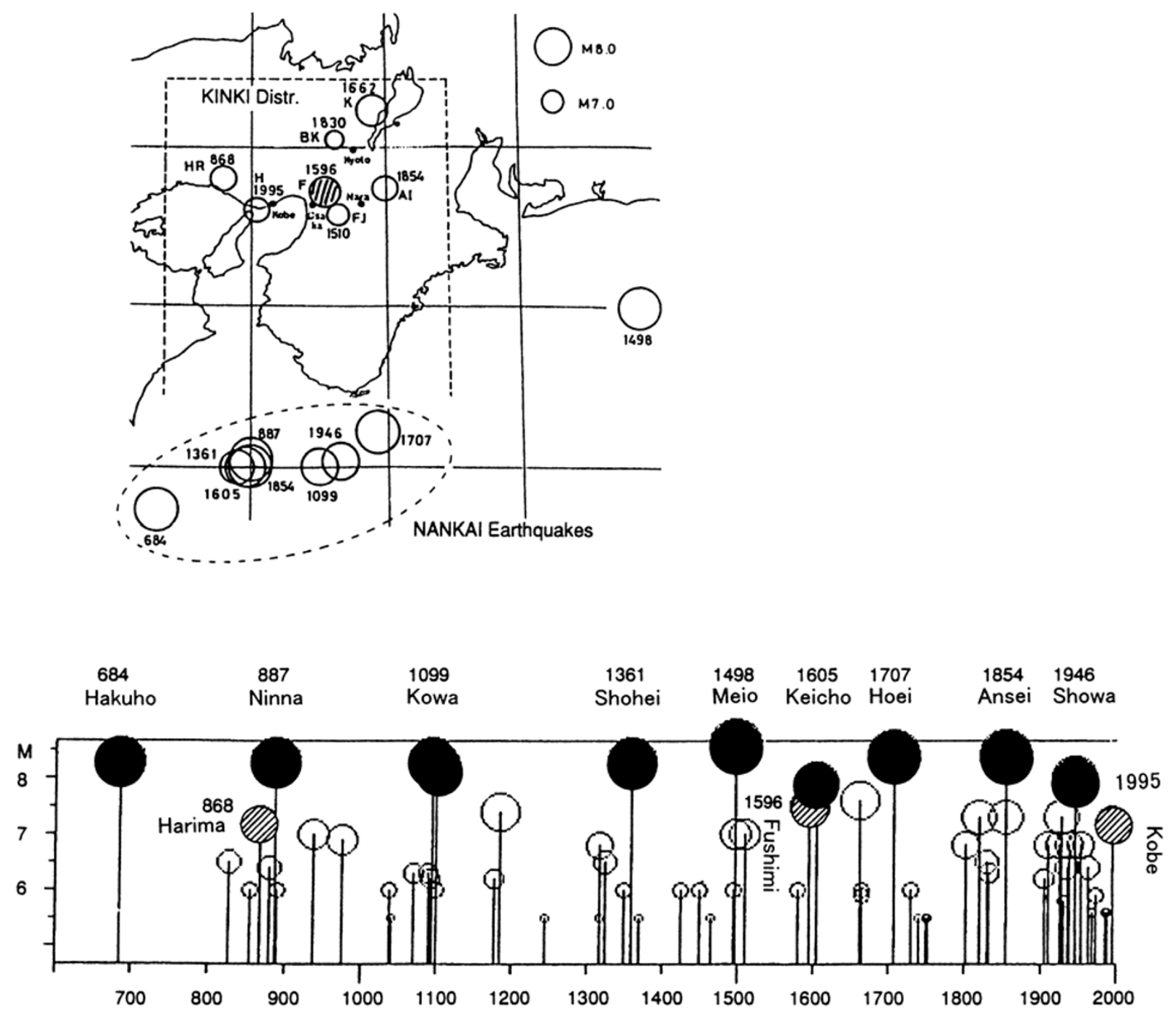

Fig. 1. Activity of large earthquakes along the Nankai trough and in the Kinki distrcit, southwestern Japan since 684 AD, modified after Tsuji (1999). The upper figure shows the epicentral distribution. The lower figure shows the Magnitude-Time plot of seismicity. Solid circles indicate events along the Nankai trough. Hatched (relatively large events) and open circles denote events that occur in the dashed rectangular region in the upper.

These studies show more complicated patterns of recurrence of large slip events at a specified fault than does the "staircase" model or the characteristic earthquake model (Schwarz and Coppersmith, 1984). In southern California, strike-slip faults such as the San Andreas fault are dominant. In southwestern Japan, on the other hand, shallowly dipping thrusts are dominant along the Nankai trough, and strike-slip faults are usually seen on land. Furthermore, slip rates of faults along the Nankai trough are several times larger than those of inland faults (e.g. Hashimoto and Jackson, 1993). Thus, the geometry of the fault system in southwestern Japan is very different from that in southern California. It is interesting to see what happens in modeled seismicity for such a different fault system.

The interplate coupling at the Nankai trough is considered to be a main controlling factor of the inland seismicity in southwestern Japan. Many studies (e.g. Utsu, 1974a, b; Shimazaki, 1976; Seno, 1979; Mogi, 1981; Hori and Oike, 1996; Tsuji, 1999) showed a temporal correlation between large inland events and interplate thrust events (Fig. 1). It is controversial, however, what mechanism is responsible for the correlation (e.g. Shimazaki, 1976; Hashimoto, 1998a; Pollitz and Sacks, 1997; Hori and Oike, 1999).

It is well known that strain rates derived from geodetic data are 10 times larger than those from historical seismicity and geological data in the Japanese islands (Wesnousky et al., 1982; Hashimoto, 1990; Ishikawa and Hashimoto, 1999). The rates obtained from the latter two datasets contain different information, since those from historical seismicity have information of only coseismic moment releases. Wesnousky et al. (1982) showed that strain rates from seismological and geological data were of the order of $10^{-8} / \mathrm{yr}$, while geodetic strain rates were larger than $10^{-7} / \mathrm{yr}$ (Hashimoto, 1990; Ishikawa and Hashimoto, 1999). The difference of geodetic strain rates from the seismological and geological strain rates is more significant than that between the latter two, and its cause must be investigated. Several ideas have been proposed to explain this discrepancy (Shimazaki, 1976; Shen-Tu and Holt, 1996; Iio, 1996; Ikeda, 1996). One possibility is that strain rates derived from historical seismicity and geological data may be underestimated because they include only coseismic strain release of large events. To examine this pos- 
sibility, it is straightforward to simulate seismicity by using fault parameters, especially slip deficit rates, derived from geodetic strain rates.

The above issues need to be solved to develop long-term forecasting methods with sufficient reliability for the public use. In this paper, we present a simple interacting fault model covering all the Japanese islands, and simulate activities of large events to examine their complexity and predictability.

\section{Scheme of Simulation}

This simulation adopts Hashimoto's (1998b) time-marching method, where the stress state of a fault at an arbitrary time is calculated by adding increments due to movements of all faults during a given time interval to the stress at the previous time step. Figure 2 shows the flow diagram of the simulation.

We simulate seismicity in a fault system model, using the results from Hashimoto and Jackson (1993) (hereafter HJ93; Fig. 3). HJ93 carried out an inversion study by dividing the Japanese islands and their surrounding regions into 19 blocks. In their model, crustal deformation was represented by the summation of the rigid motion of blocks and the elastic deformation due to slip deficits on the boundary faults between blocks. They estimated both block motions and slip deficit rates from the 100-year triangulation and trilateration data and Very Long Baseline Interferometry (VLBI) velocities. The fault system model used in the present study includes all faults of HJ93 in and around the Japanese islands. Each fault is divided into four elements: i.e. two in the strike and two in the dip directions. There are 104 faults in the model, leading to 416 elements. All fault elements are assumed to be rectangular with uniform slip deficit rates that are the same as those of the original faults in HJ93. The smallest element is $15 \mathrm{~km} \times 10 \mathrm{~km}$, which corresponds to about the size of a M6 earthquake. The rectangles in Fig. 3 are surface projections of dipping fault planes of the original HJ93 and the thick

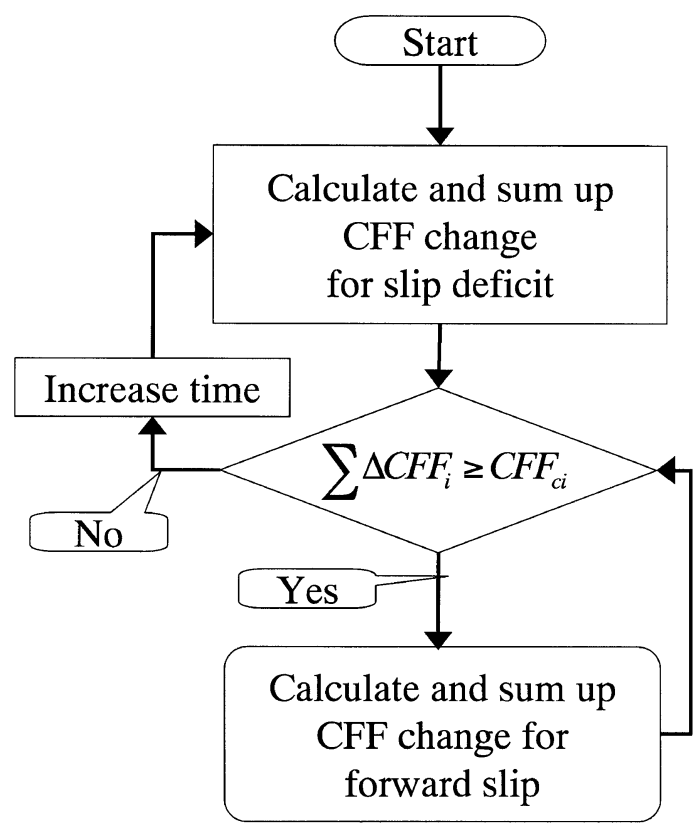

Fig. 2. Flow diagram of calculation in this model. lines show their upper edges. Strike-slip faults are indicated with parallel arrows.

Mechanical interactions between faults are represented by changes in the Coulomb Failure Function (hereafter $\triangle \mathrm{CFF}$ ) in the preferred slip direction of each fault as induced by slip on other faults. $\triangle \mathrm{CFF}$ is defined as

$$
\Delta \mathrm{CFF}=\Delta \tau-\mu\left(\Delta \sigma_{n}-\Delta P\right)
$$
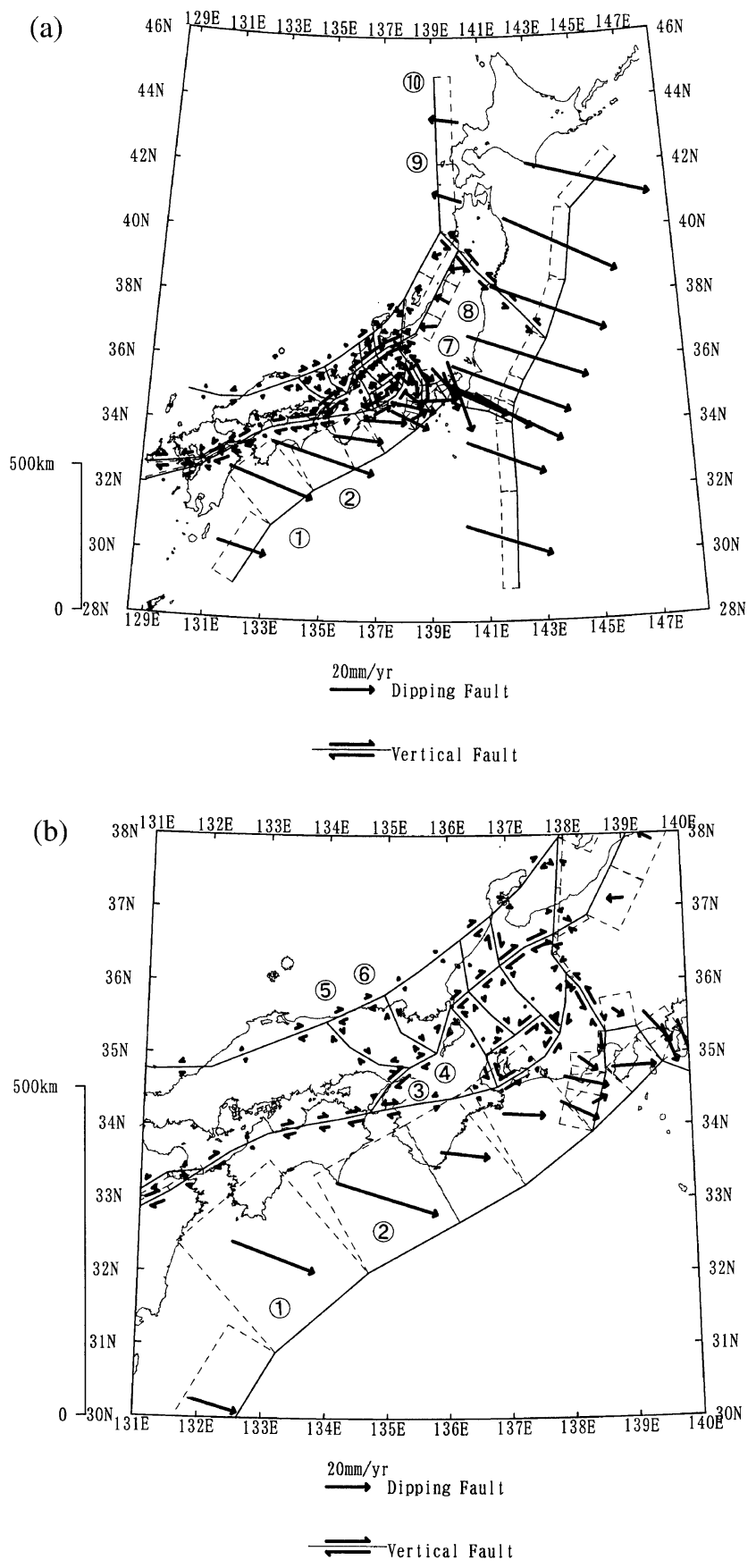

Fig. 3. Fault system model after Hashimoto and Jackson (1993). Arrows show slip deficit rates derived from 100 year geodetic data. (a) Entire Japanese island region, (b) close-up of southwestern Japan. Numbers indicate the faults whose stress and seismic activity are discussed in text: (1) off eastern Shikoku, (2) off western Shikoku, (3) Rokko fault, (4) Arima-Takatsuki Tectonic Line (ATTL), (5) Shikano fault, (6) fault NE of Tottori, (7) Shinanogawa Seismic Zone, (8) fault near Niigata, (9) off northwestern Honshu, and (10) off western Hokkaido. 
where $\Delta \tau$ and $\Delta \sigma_{n}$ are changes in shear stress parallel to the direction of slip, and normal stress (compression is positive), respectively. $\Delta P$ is the change in pore pressure, and $\mu$ is the coefficient of friction. A reduced value of the coefficient of friction is often used to incorporate the effect of pore pressure change (e.g. King et al., 1994). Thus, using Skempton's coefficient $B$,

$$
\Delta \mathrm{CFF}=\Delta \tau-\mu(1-B) \Delta \sigma_{n}=\Delta \tau-\mu^{\prime} \Delta \sigma_{n}
$$

Here we use 0.4 for the reduced coefficient of friction, because this value could explain the postseismic seismicity change around the source region of the 1995 Kobe earthquake (e.g. Hashimoto, 1995, 1997). $\triangle \mathrm{CFF}$ is evaluated at the center of each element on modeled faults. We assume a perfectly elastic half space with a rigidity of $40 \mathrm{GPa}$ and Poisson's ratio of 0.25 in the calculation of stress caused by a dislocation using Okada's (1992) formula. We adopt the rake of slip deficit rate from HJ93 for the preferred slip of each fault. The preferred slip is assumed to be the same for all the elements on a fault. The first step of the simulation is to calculate $\triangle \mathrm{CFF}$ of every element on all faults due to a unit slip of one element and store the results in a matrix. I call this matrix the "interaction matrix" in this paper. Be aware that the derivation and definition of the interaction matrix are different from those in Rundle and Kanamori (1987) and Rundle (1988a). In this paper, the time interval is 1 year.

We set the initial state of the elements by randomly perturbing stresses between 0 and the threshold for rupture. Beginning from this initial state, stresses of all faults change as follows. Stages of fault activity are divided into two categories in the present model: stress accumulation due to slip deficit and release by forward-slip. Slip deficit represents the accumulation process (Savage, 1982; Matsu'ura et al., 1986), while forward-slip is an earthquake. When accumulated $\triangle \mathrm{CFF}$ for a fault exceeds its rupture threshold, a forward-slip occurs and stresses are redistributed according to the interaction matrix and the amount of slip. The forwardslip is calculated simply by dividing the accumulated stress by the stiffness (i.e. diagonal components of interaction matrix). In this study, we assume that the forward-slip releases all the accumulated stress for the rupturing element and that the rupture threshold is constant with time. This assumption implies that the forward-slip is nearly constant, because the accumulated stress is nearly equal to the rupture threshold. The size of the forward-slip fluctuates slightly due to the perturbation by other rupturing elements. In this model, we do not include slow slips on faults. Therefore the size of an event is proportional to the number of elements of the fault that rupture simultaneously. The rate of the stress increase on one element is the sum of the contribution from the slip deficits of all the elements in the entire system. The condition that the cumulative stress of an element exceeds the rupture threshold is checked at every time step. If there is a rupturing element, the accumulated stress is redistributed and added to the other elements. After adding stress changes to other elements, the check for rupture threshold is made again for all elements. The interaction continues until no rupturing elements are found. If there are no rupturing elements, calculation goes to the next time step. The calculation continues for an arbitrary time. We calculate a stress history for 10,000 years in order to see many events at all faults to discuss the recurrence behavior. The rupture threshold is the parameter that controls the timing of rupture and the magnitude of slip. We assume a threshold of 0.5 and 2.0 $\mathrm{MPa}$ for interplate and inland faults, respectively, using the original fault model of HJ93 is used without dividing into elements (Hashimoto, 1998b). These are roughly equivalent to forward-slips of $4 \sim 6 \mathrm{~m}$ for interplate boundaries, such as the Nankai and Suruga troughs, and $2 \mathrm{~m}$ for inland faults in Hashimoto (1998b).

\section{Results}

Here we present preliminary results for the present model based on HJ93. To see if there is a correlation of activity between interplate faults along the Nankai trough and inland faults in southwestern Japan, we observe temporal variations in average stresses of the 4 elements in each fault and the history of forward-slip events (i.e. earthquakes). We also examine the effect of small perturbations of initial stresses.

\subsection{Temporal variation in average stresses and history of forward-slip events}

Figure 4 shows the temporal variation in average $\triangle \mathrm{CFF}$ during the first 5,000 years of (a) the two model faults off Shikoku, (b) the model Arima-Takatsuki Tectonic Line and the Rokko fault, and (c) the model faults near the Tottori area, one of which corresponds to the Shikano fault. It is clearly seen that the rate of stress accumulation is not constant for several faults, especially the faults off Shikoku and the Arima-Takatsuki Tectonic Line. Patterns of temporal stress changes are complicated, and the same pattern never appears twice. $\triangle \mathrm{CFF}$ change on the fault off eastern Shikoku has more high frequency components than that of its western neighbor. This may be attributed to the difference in slip deficit rates and sizes of fault elements. Furthermore, the fault off eastern Shikoku may be affected much by the stress changes in the surrounding faults, because they are closely located. We can recognize that the amplitudes of stress change fluctuate temporally with a period of 1,500 years or longer for the Arima-Takatsuki Tectonic Line, Rokko, and Shikano faults (Figs. 4(b) and (c)). Therefore it seems inappropriate to apply histories of a period shorter than 1,500 years for forecasting future events.

Figure 5 shows a history of forward-slip events during the first 5,000 years. Forward-slips on an element are converted to seismic moments by multiplying the area and the rigidity summed over the four elements. It is clear that there are events of various sizes, corresponding to the simultaneous rupture of one, two, three or all four elements of each fault. Events rupturing shallower elements that break the surface have larger slips than those that rupture deeper elements only, because the diagonal component of interaction matrix, which is equivalent to the stress drop of an event with unit slip, are smaller for shallower elements than that for deeper elements. Therefore there are two different sizes of events that rupture a single element on a fault. Events that rupture all four elements rarely occur. Events that rupture three elements are also relatively rare, with intervals longer than 1,000 years for inland faults. In the model of Hashimoto (1998b), faults were not subdivided and whole-fault ruptures occurred frequently. The less frequent occurrence of large 


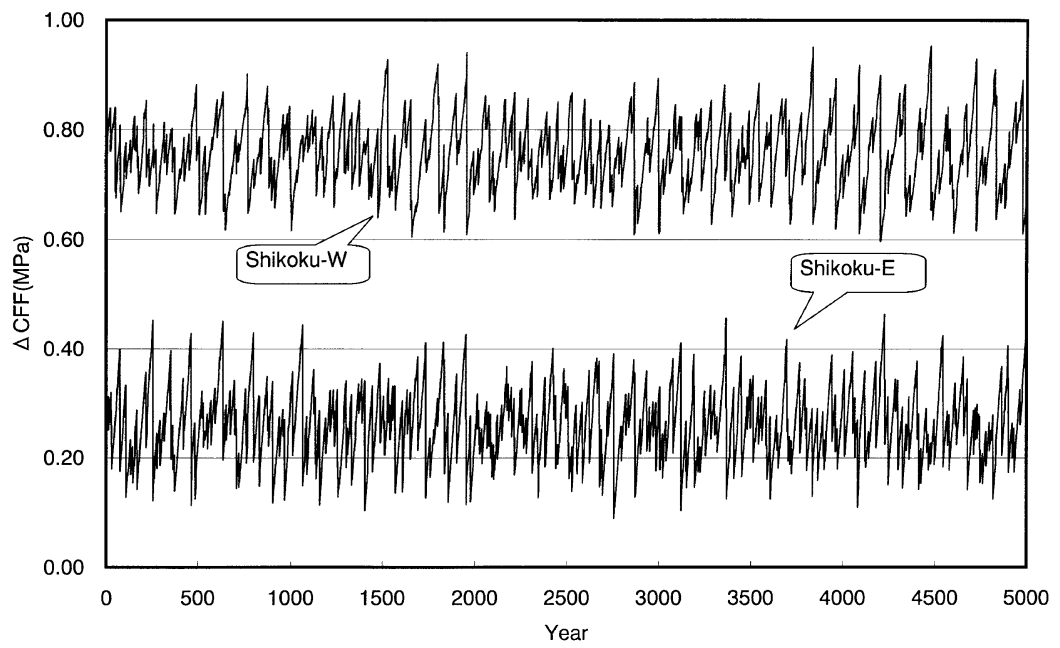

(a)

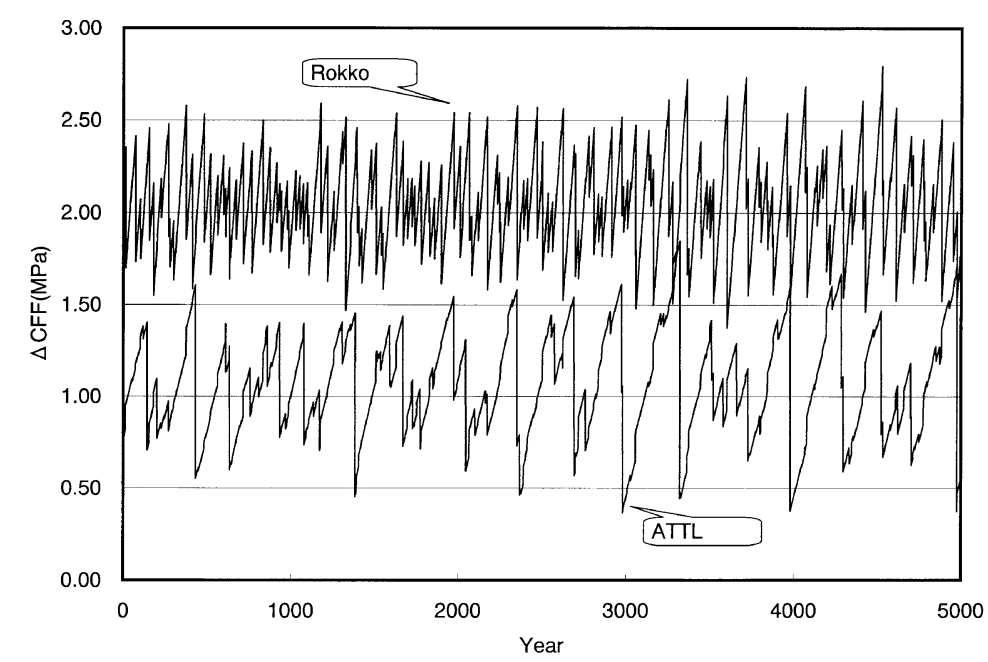

(b)

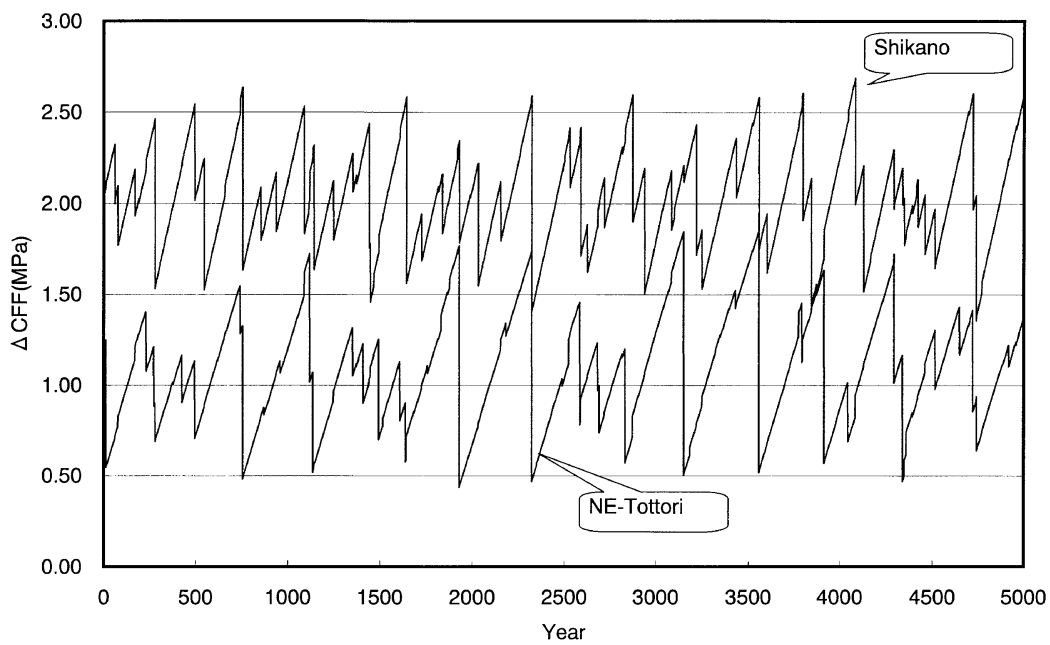

(c)

Fig. 4. Simulated temporal variations in average stresses on specific faults during 5,000 years: (a) Interplate faults off Shikoku (1) and (2) in Fig. 2), (b) the Rokko fault (3)) and the Arima-Takatsuki Tectonic Line (4)), (c) the Shikano fault (5), and its NE extension (6)). 


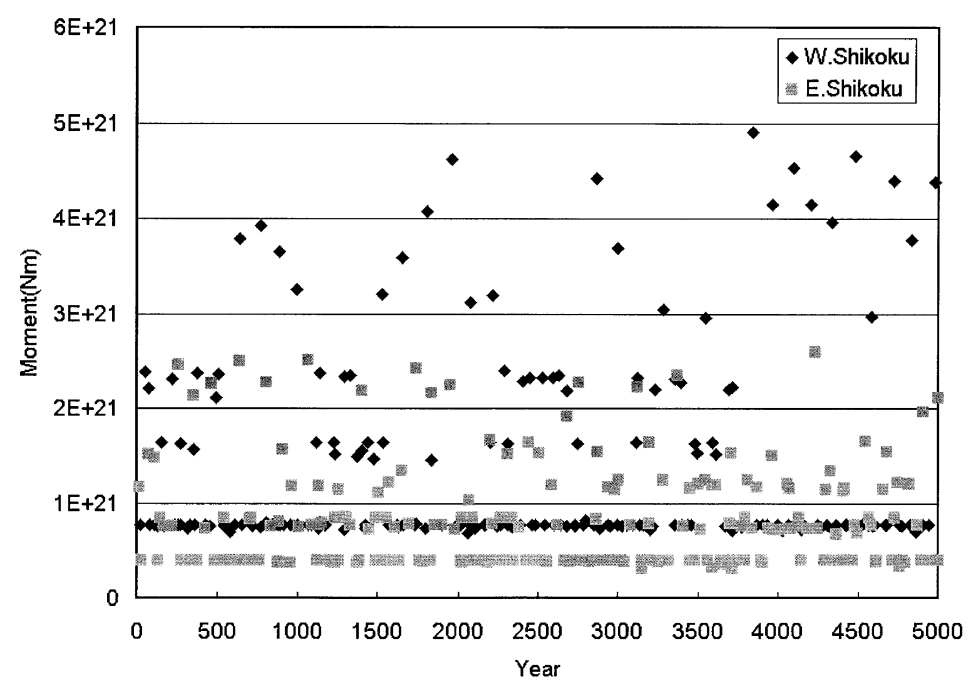

(a)

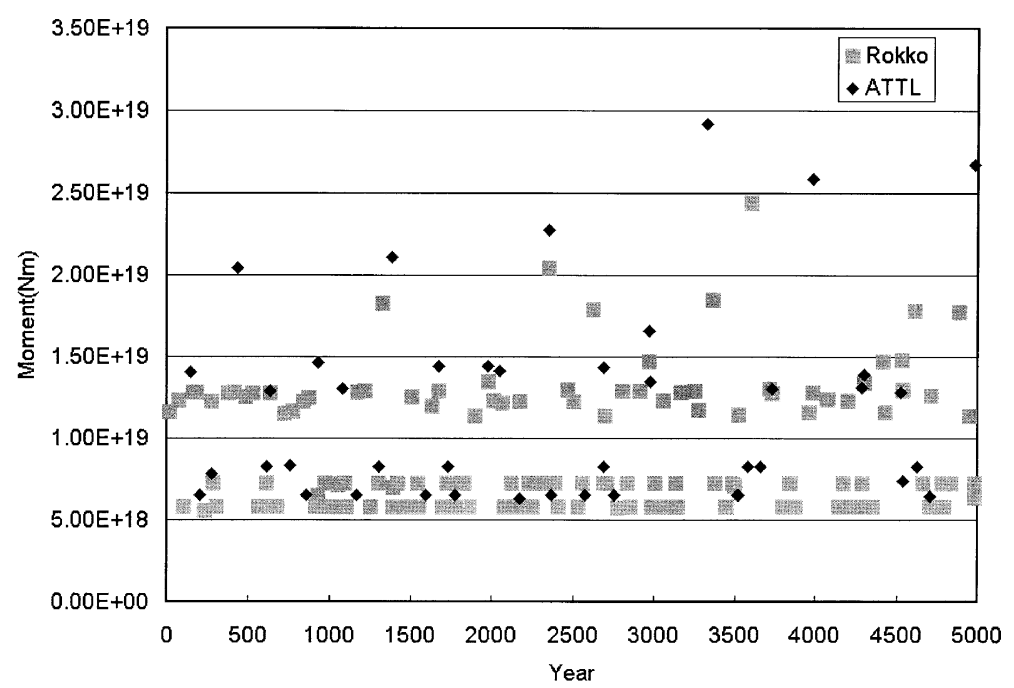

(b)

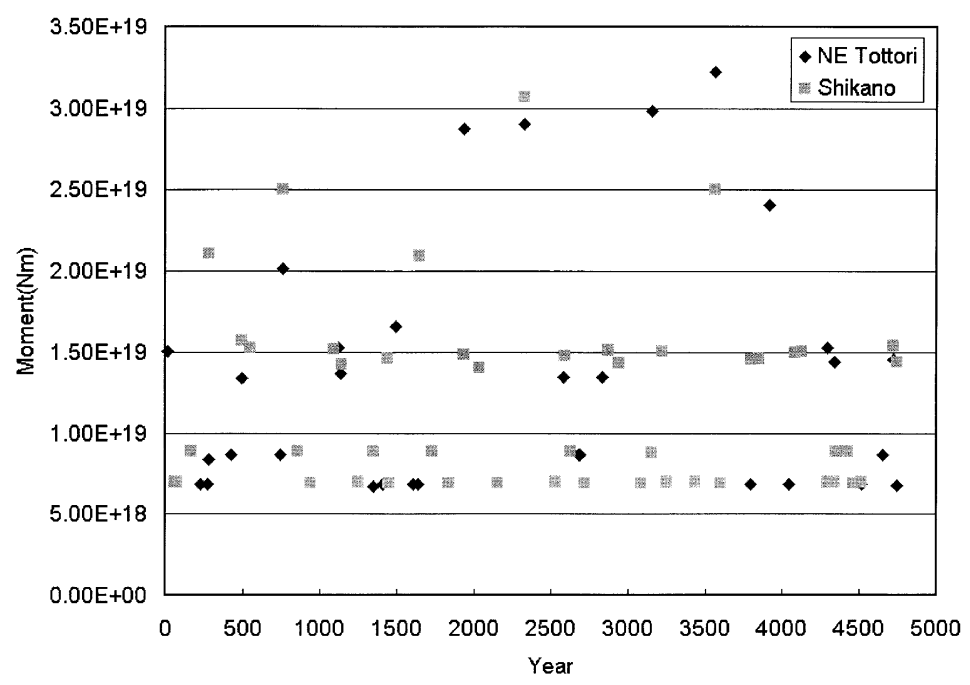

(c)

Fig. 5. Seismic moment-time relationship of simulated forward-slip events on specific faults during the first 5,000 years: (a) Interplate faults off eastern and western Shikoku, (b) the Rokko fault and the Arima-Takatsuki Tectonic Line, (c) the Shikano fault and its NE extension. Solid diamonds indicate the stress state at the designated years (attached numbers). 


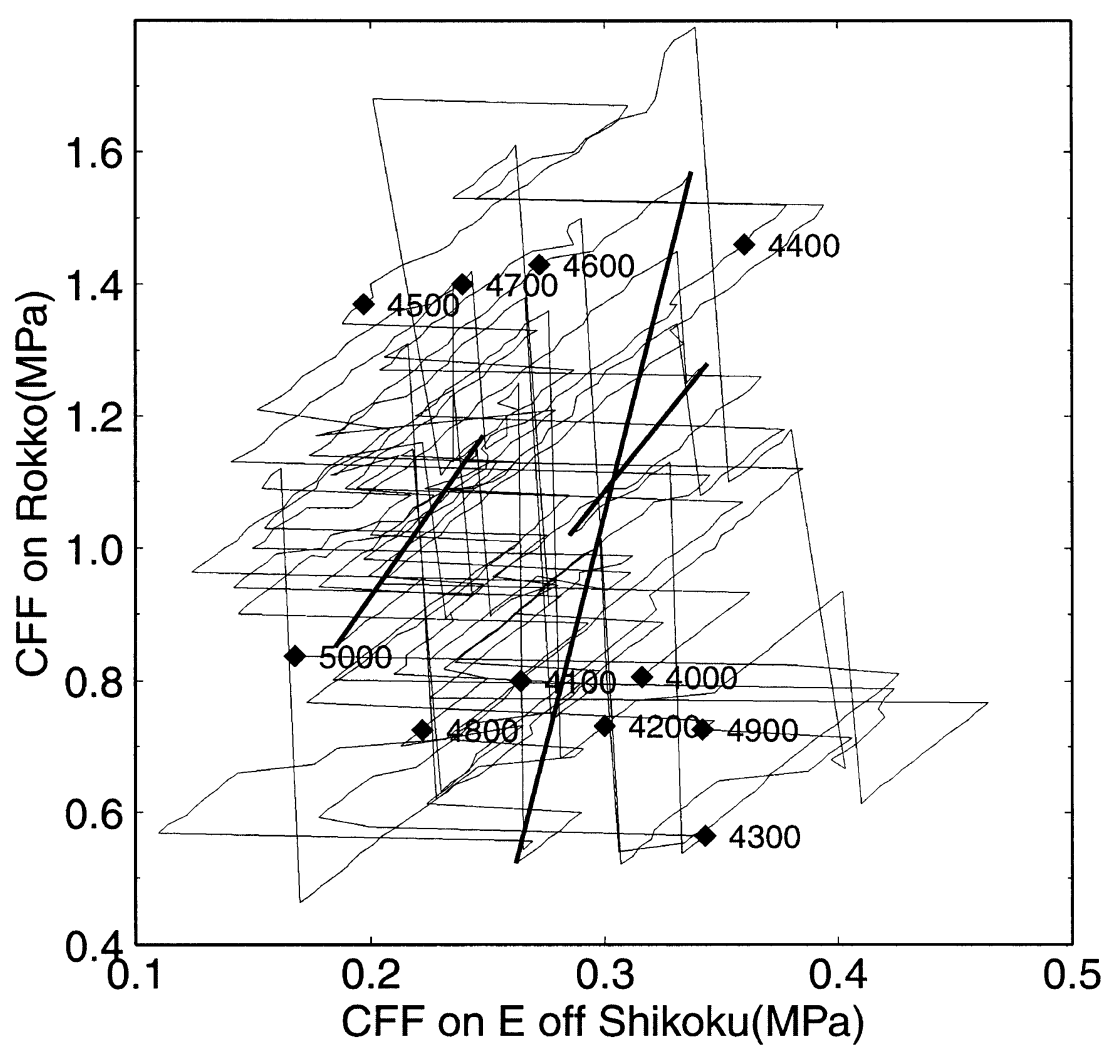

(a)

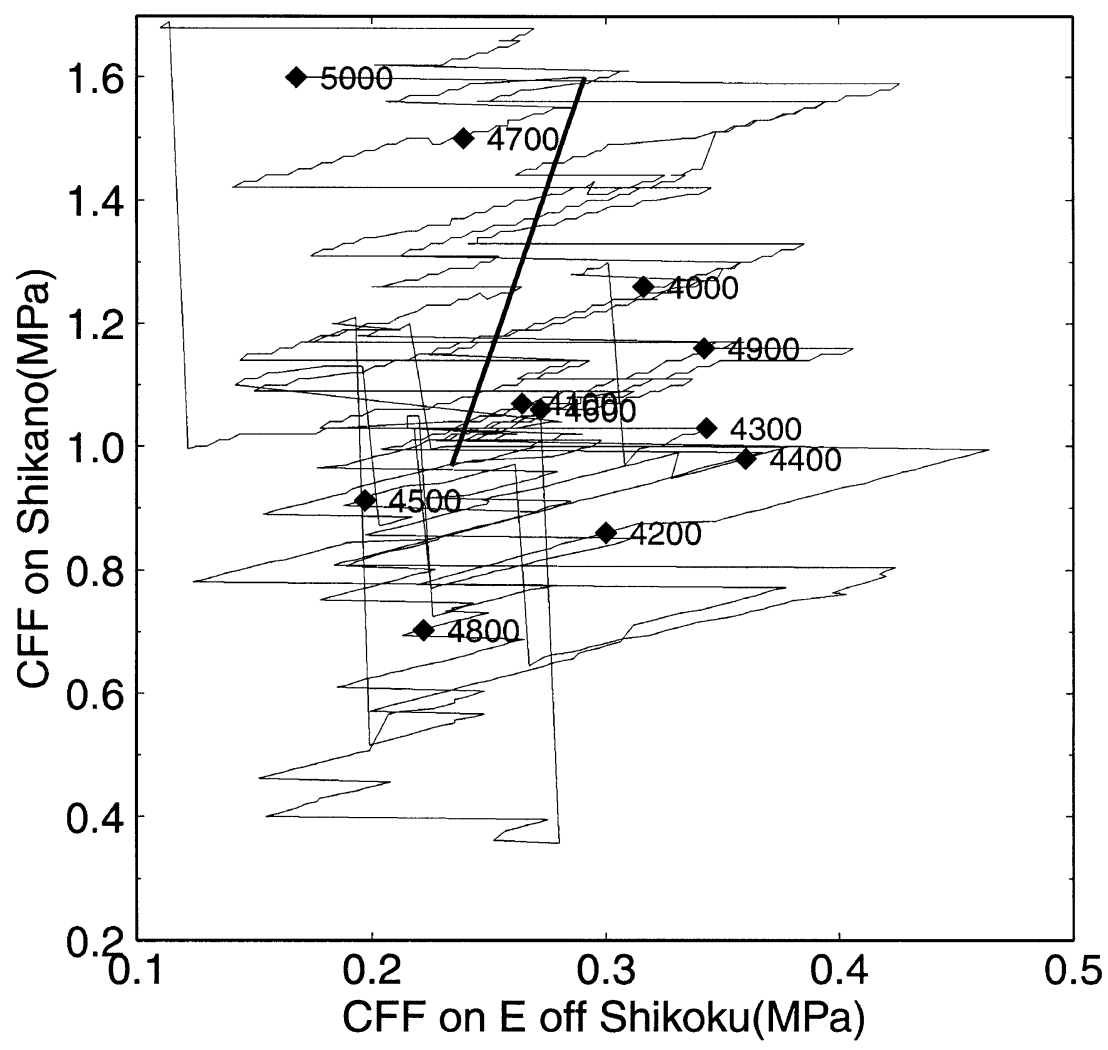

(b)

Fig. 6. State space diagrams for selected pairs of faults: (a) the Rokko fault and the fault off eastern Shikoku, (b) the Shikano fault and the fault off eastern Shikoku. Each diagram shows the relation of the time history of stress for the pair of faults. Thick lines indicate simultaneous events of slips on both faults. 
Magnitude vs Frequency

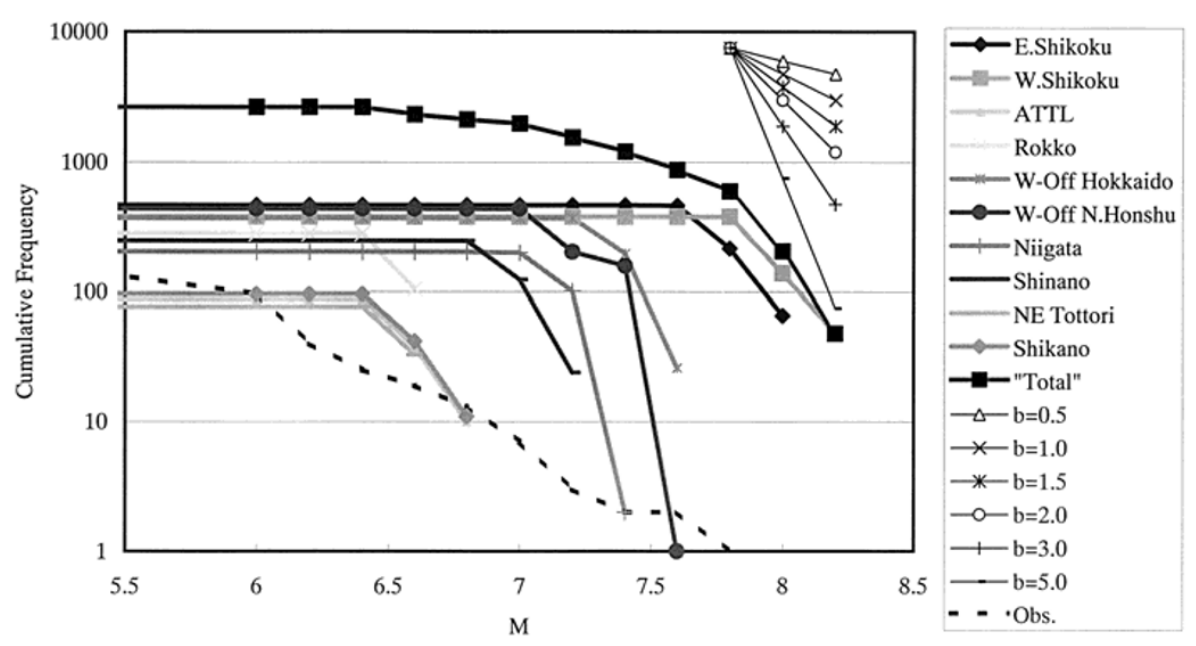

Fig. 7. Magnitude-cumulative frequency relationship for modeled forward-slip events on several faults (numbered in Fig. 3). "Total" shows the distribution for all the faults included in this figure. Obs. shows the distribution for earthquakes $\left(M_{\mathrm{JMA}}>4.0, H<40 \mathrm{~km}\right)$ that occurred in and around southwestern Japan $\left(30^{\circ} \sim 37^{\circ} \mathrm{N}, 129^{\circ} \sim 139^{\circ} \mathrm{E}\right)$ during the period from January 1926 to December 1998 . Earthquake data are obtained from the JMA catalog.

events in the present model is the result of dividing faults into smaller elements. For interplate faults along the Nankai trough, larger events with the rupture of three or four elements occur much more frequently (more than 24 events on the fault off western Shikoku in 5,000 years) than inland faults ( 13 events on the Rokko fault and the ATTL). However, their size and recurrence intervals are very irregular. Furthermore events smaller than M8 occur very frequently along the Nankai trough. About 240 and 190 events occur on the faults off eastern and western Shikoku, respectively, in 5,000 years. This is discordant with the observed seismicity, since $3 \sim 4$ events of M7 have occurred off southwestern Japan during the recent 100 years according to figure 3 in Ando (1999). Therefore to model the seismicity more realistically in the future, we must incorporate several conditions such as depth dependence of friction parameters, rupture thresholds etc.

\subsection{Correlation between activities of interplate and in- traplate faults}

To examine the correlation between interplate and intraplate events, we prepare phase diagrams in which average stresses of inter- and intraplate faults are the ordinate and abscissa, respectively. Figure 6 shows the phase diagram for the fault off eastern Shikoku and the Rokko and Shikano faults, respectively, during the period from 4,000 to 5,000 years. The gentle-slope lines indicate the stress accumulation processes of both faults. Horizontal and nearly vertical lines show forward-slip events on the fault off eastern Shikoku and the Rokko or Shikano fault, respectively. We can recognize three and one lines, respectively in Figs. 6(a) and 6(b), with a rather steep slope (thick lines). These are events when the Rokko or Shikano faults had forward slips simultaneously with the slip at the fault off eastern Shikoku. There are 26 forward-slip events on the Rokko fault and 10 on the Shikano fault during this period and 3 and 1 of them, respectively, are accompanied by the events on the fault off eastern Shikoku.

However, these simultaneous occurrences might be a mat- ter of coincidence, since events on the Nankai trough occur frequently. Most of these events are small with only one rupturing element. Figure 7 shows the cumulative magnitudefrequency relationship on each fault. It is clear that each fault has a lower limit of magnitude which is due to the element size and a "b-value" much larger than 1. Events of medium sizes may occur more frequently in this simulation than in the real world. Therefore to simulate seismicity more realistically in the future we would like to use much smaller elements.

\subsection{Effects of perturbation of initial stresses}

To examine the effect of perturbations to the initial stresses, we changed the initial stresses by $1 \%$ and reran the simulation. Figure 8 shows temporal changes in distance in the state space between two models that have a $1 \%$ difference in the initial stresses of all the elements. This state space is a coordinate system whose components are stresses of all elements. It is clear that the distance between these two models increases with time, with very short-term fluctuations superimposed. The open circle in Fig. 8(a) indicates the distance ( $\sim 0.1 \mathrm{MPa}$ ) at the beginning of the simulation. After several hundred years, the distance increases up to about $2 \sim 3 \mathrm{MPa}$, which is $20 \sim 30$ times larger than the value at the beginning of the simulation. In this case, the increase of distance is slow after 3,000 years. In a couple of cases with different intial conditions, the distance increases linearly with time (Fig. 8(b)). In the present model, there is a pair of segments that nearly overlapped but belong to different faults at the Suruga trough, the eastern end of the Nankai trough. They strongly affect each other, and if one of segments ruptures first the other never ruptures. Therefore the distance in the phase space increase linearly with time. This may be an artifact of the present model, and we must investigate it in the future studies.

The above results cast a serious problem for a long-term forecast of large events. In order to make an accurate forecast, we must observe stresses with less than a few percent errors 


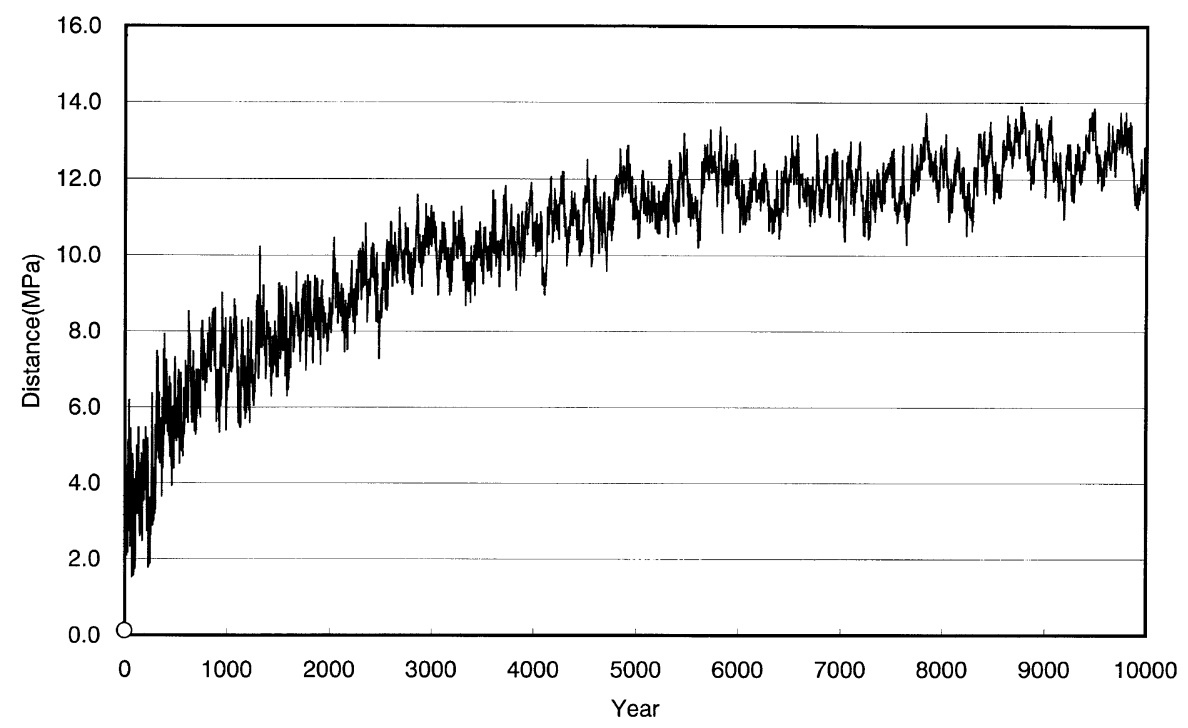

(a)

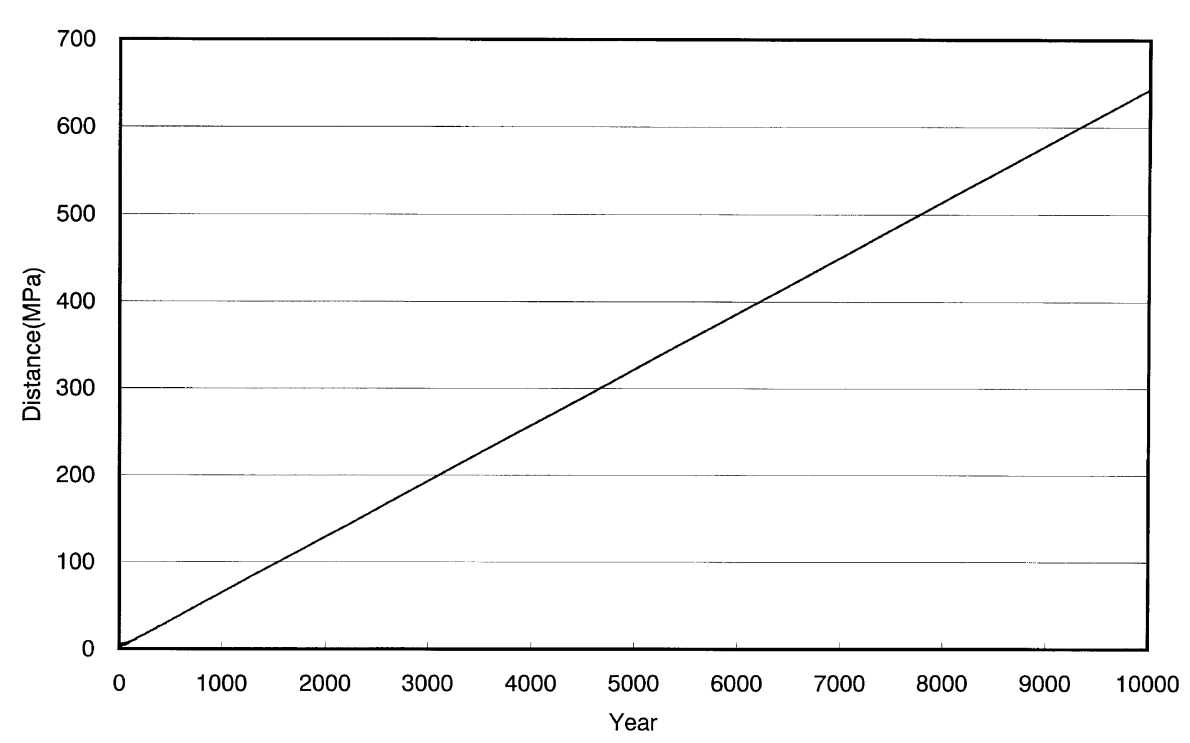

(b)

Fig. 8. Temporal variation in distance between two models with differences in initial stresses of $1 \%$ in state space. Open circle shows the distance at the beginning of the simulations. (a) The case of slow distance increase. (b) The case of linear distance increase.

for all faults, but this seems unlikely at the present. Therefore to better represent this type of fluctuating repeat times that depend strongly on the initial conditions, it is important to develop a probabilistic method to forecast large events.

\section{Discussion}

Simulations of seismicity taking into consideration mechanical interactions between faults suggest a wide variety in the behavior of faults. Rundle (1988b), Ward (1991), and Ward (1996) obtained similar results for southern California and the Middle America Trench. This study confirms that a variety of recurrence behavior also arises from mechanical interactions between faults in a fault system such as in Japan. The main differences between the present and the preceding studies are in the dimension of the model, the constitutive law, and the size of the smallest element. The present study uses $\triangle \mathrm{CFF}$ to represent interactions between faults to reduce the number of parameters. We adopt slip deficit rates derived from geodetic data for the accumulation of stress on the fault. However, we have used a very simple friction law. To improve the model we must incorporate a more realistic friction law in the future.

It is noteworthy that the rate of stress accumulation on a fault is not always constant. This result contradicts a common assumption in most earthquake recurrence models. Events would occur periodically if there is no interaction between faults (Rundle, 1988a; Hashimoto, 1998b). Stress accumulation on a fault is no longer constant in an interacting fault model. This means that we must know the movements of surrounding faults precisely if a deterministic prediction is to be made. This is not possible at the present. Although we can utilize a dense array of GPS (Global Positioning 
System) observations in Japan, slip rate and fault geometry estimates are accompanied by many errors. Furthermore we cannot incorporate all the characteristics of a real fault system into models, because of limitations in modeling and possible existence of unknown buried faults. Therefore we should redirect our efforts from deterministic predictions to more probabilistic forecasts of earthquake occurrence.

Slip rates of several faults have been estimated from geological studies, but not for all the faults under consideration. On the other hand, geodetic data covers the whole Japanese islands. Therefore in our modeling we consider it more appropriate to use slip deficit rates constrained by geodetic data. These slip deficit rates are estimated using dislocations in a perfectly elastic medium. It is well known that geodetic strain rates are larger by a factor of 10 than strain rates derived from geological and seismological data in the Japanese islands (Wesnousky et al., 1982; Hashimoto, 1990; Iio, 1996; Ikeda, 1996; Ishikawa and Hashimoto, 1999). For example, the MTL and the Atotsugawa fault have slip deficit rates of about $10 \mathrm{~mm} / \mathrm{yr}$ as estimated from geodetic data (Hashimoto and Jackson, 1993), but slip rates of these faults from geological data are about $1 \mathrm{~mm} / \mathrm{yr}$ (Research Group for Active Faults in Japan, 1991). Shen-Tu and Holt (1996) suggested that the strain rates in northern Honshu during the recent 100 years were elastic and were due to the subduction of the Pacific plate. However, this type of elastic loading model cannot be fully applied to southwestern Japan where other factors such as the motion of the Amurian plate must be considered (Le Pichon et al., 1998). Iio (1996) pointed out that geodetic strain rates contain inelastic components and suggested that aseismic creep of inland faults at the depth of seismogenic zone might play an important role. One explanation for the difference between the geodetic and geologic strain rates can be made by comparing the present study with that of Hashimoto (1998b), which carried out a simulation using the original fault system model of HJ93. In Hashimoto (1998b), events always rupture the whole area of a fault, and recurrence intervals of events were about 100 years for the Nankai trough and about 300 years for the Rokko fault. In the present study, however, dividing a fault into smaller elements results in much longer intervals between large events that rupture the whole fault. Therefore we hypothesize that the slip of a small fault patch may release a significant part of the accumulated strains in small events, and that large events that rupture multiple patches simultaneously, which can be recognized as "characteristic earthquakes", occur much less frequently. However, contrary to our model, Peterson and Seno (1984) pointed out that moderate-size events might not contribute to moment release in subduction zones. Considering the magnitude-frequency distribution, moderate-size events occur too frequently in our present results. In subduction zones around the Japanese islands, aseismic moment release has been recognized (e.g. Heki et al., 1997; Kawasaki et al., 1998). Our model assumes that all the accumulated stress is released in a single seismic event. For future calculations we need to include the aseismic moment release.

The present model assumes an elastic half space, rectangular faults, and uniform slips of each fault element. These assumptions cause large stress concentrations near the edges of faults that may affect model seismicity, depending on where stresses are evaluated on each fault. As seen in Fig. 7 this model cannot produce a power-law distribution of the magnitude-frequency relationship with a b-value nearly equal to 1 , although using fault elements of smaller size may solve this discrepancy. Furthermore, a forward-slip causes instantaneous changes in stress in the surrounding region, because of the assumption of perfect elasticity. A time delay of stresses due to a viscoelastic response of the asthenosphere, such as suggested in Rundle (1988b), is not considered in this calculation. As mentioned above, we need to improve our model by using smaller elements and including the effects of viscoelasticity. We also need to improve the fault constitutive relation and healing process to simulate more realistically the recurrence intervals and statistical characteristics such as the Gutenberg-Richter's law.

As discussed above, this study suggests that even small changes in parameters cause large differences in the resultant seismicity, especially the timing of large events after hundreds of years. This may point to a serious problem in the long-term forecast of earthquake occurrence. Even if simulators of crustal activity including above factors can be developed, successful forecasts are not possible unless estimates of parameters are extremely accurate. As seen in Fig. 8, differences between two models with similar initial states can increase in a very complicated fashion. No simple law of error propagation can be readily applied. Therefore it is necessary to develop a method to estimate errors in the forecast as well as to develop an earthquake simulator itself.

\section{Conclusion}

Occurrences of large events in southwestern Japan are simulated taking into account mechanical interactions between faults, and the following results are derived:

1) The rate of stress accumulation on a fault element is not always constant because of fault interaction, contradicting what is commonly assumed in most earthquake recurrence models.

2) A variety of sizes of events occur according to the number of simultaneously rupturing elements if model faults are divided into smaller elements. Large events that rupture the whole fault area occur less frequently than in the model in which the faults are not divided into smaller elements. The difference between geodetic and geological/seismological strain rates might be made up by smaller events.

3) Fluctuations in the amplitude of stress changes with periods of 1,500 years or longer are seen for some inland faults.

4) The distance in state space between two models with small perturbations in the initial stresses increases by a factor of about 20 30 times after several hundred years. This poses a serious problem for long-term deterministic forecasts of earthquake occurrence.

Acknowledgments. I would like to express sincere thanks to Prof. Masataka Ando who gave me an opportunity to present this research in the symposium. I also thank Drs. Kelin Wang, Tetsuzo Seno, 
James Mori, and an anonymous reviewer for their critical comments. This research is partly supported by the Grand-in-Aid for Scientific Research (C) No. 10640407, and the Promotion and Coordinating Fund for Science and Technology (Research on the Development of Parallel Software for the Precise Forecast of the Earth's Evolution). A couple of figures are prepared by GMT ver.3.0 by Wessel and Smith (1991).

\section{References}

Ando, M., What should Japan do for the next Nankai earthquake?, in "The Nankai earthquake-prepared for the next great earthquake", Chikyu (Earth Monthly), Special Issue, 24, 5-13, 1999 (in Japanese).

Bak, P. and C. Tang, Earthquakes as a self-organized critical phenomenon, J. Geophys. Res., 94, 15535-15537, 1989.

Burridge, R. and L. Knopoff, Model and theoretical seismicity, Bull. Seism. Soc. Am., 57, 341-371, 1967

Carlson, J. M. and J. S. Langer, Mechanical model of an earthquake fault, Phys. Rev., A40, 6470-6484, 1989.

Harris, R. A. and R. W. Simpson, Changes in static stress on southern California faults after the 1992 Landers earthquake, Nature, 360, 251254, 1992.

Hashimoto, M., Horizontal strain rates in the Japanese Islands during interseismic period deduced from geodetic surveys (Part I): Honshu, Shikoku and Kyushu, Zisin (J. Seism. Soc. Japan), Ser. 2, 43, 13-26, 1990 (in Japanese with English abstract).

Hashimoto, M., Static stress changes associated with the Kobe earthquake: Calculation of changes in Coulomb failure function and comparison with seismicity change, Zisin (J. Seism. Soc. Japan), Ser. 2, 48, 521-530, 1995 (in Japanese with English abstract)

Hashimoto, M., Correction to "Static stress changes associated with the Kobe earthquake: Calculation of changes in Coulomb failure function and comparison with seismicity change", Zisin (J. Seism. Soc. Japan), Ser. 2, 50, 21-27, 1997 (in Japanese with English abstract).

Hashimoto, M., Simulation of temporal variation in Coulomb failure functions in the source region of the Hyogo-ken Nanbu earthquake, Zisin ( $J$. Seism. Soc. Japan), Ser. 2, 50, Suppl., 229-249, 1998a (in Japanese with English abstract).

Hashimoto, M., Simulation of activity of large earthquakes in and around the southwest Japan on the basis of slip deficit model, Annuals of Disaster Prevention Research Institute, Kyoto Univ., 41, B-1, 45-59, 1998b.

Hashimoto, M. and D. D. Jackson, Plate tectonics and crustal deformation around the Japanese islands, J. Geophys. Res., 98, 16149-16166, 1993.

Headquarters for Earthquake Research Promotion, On the evaluation and survey results for Itoigawa-Shizuoka Tectonic Line fault zone, Report from the Headquarters for Earthq. Res. Promotion, 1997a (in Japanese).

Headquarters for Earthquake Research Promotion, On the evaluation and survey results for Kan'nawa-Kouzu-Matsuda fault zone, Report from the Headquarters for Earthq. Res. Promotion, 1997b (in Japanese).

Headquarters for Earthquake Research Promotion, On the evaluation and survey results for Fujikawa-kako fault zone, Report from the Headquarters for Earthq. Res. Promotion, 1998 (in Japanese).

Heki, K., S. Miyazaki, and H. Tsuji, Silent fault slip following an interplate thrust earthquake at the Japan trench, Nature, 386, 595-598, 1997.

Hori, T. and K. Oike, A statistical model of temporal variation of seismicity in the Inner Zone of southwest Japan related to the great interplate earthquakes along the Nankai trough, J. Phys. Earth, 44, 349-356, 1996.

Hori, T. and K. Oike, A physical mechanism for temporal variation in seismicity in the Inner Zone of southwest Japan related to the great interplate earthquakes along the Nankai trough, Tectonophys., 308, 83-98, 1999.

Huang, J. and D. L. Turcotte, Evidence for chaotic fault interactions in the seismicity of the San Andreas fault and Nankai trough, Nature, 348, 234-236, 1990.

Hudnut, K. W., L. Seeber, and J. Pacheco, Cross-fault triggering in November 1987 Superstition Hills earthquake sequence, southern California, Geophys. Res. Lett., 16, 199-202, 1989.

Iio, Y., A possible generating process of the southern Hyogo Prefecture earthquake-Stick of fault and slip on detachment, Zisin (J. Seism. Soc. Japan), Ser. 2, 49, 103-112, 1996 (in Japanese with English abstract).

Ikeda, Y., Implications of active fault study for the present-day tectonics of the Japan arc, Active Fault Research, 15, 93-96, 1996 (in Japanese with English abstract).

Ishikawa, N. and M. Hashimoto, Average horizontal crustal strain rates in Japan during interseismic period deduced from geodetic surveys (part 2), Zisin, (J. Seism. Soc. Japan), Ser. 2, 52, 299-315, 1999 (in Japanese with
English abstract).

Ito, K. and M. Matsuzaki, Earthquake as self-organized critical phenomena, J. Geophys. Res., 95, 6853-6860, 1989.

Jaumè, S. C. and L. R. Sykes, Changes in state of stress on the southern San Andreas fault resulting from the California earthquake sequence of April to June 1992, Science, 258, 1325-1328, 1992.

Kawasaki, I., Y. Asai, and T. Tamura, Interplate moment release in seismic and seismo-geodetic bands and the seismo-geodetic coupling in the Sanriku-Oki region along the Japan trench, Zisin (J. Seism. Soc. Japan), Ser. 2, 50, Suppl., 293-307, 1998 (in Japanese with English abstract).

King, G. C. P., R. Stein, and J. Lin, Static stress changes and the triggering of earthquakes, Bull. Seism. Soc. Am., 84, 935-953, 1994.

Le Pichon, X., S. Mazzotti, P. Henry, and M. Hashimoto, Deformation of Japanese islands and seismic coupling: an interpretation based on GSI permanent GPS observations, Geophys. J. Int., 134, 501-514, 1998

Matsuda, T., Estimation of future destructive earthquakes from active faults on land in Japan, J. Phys. Earth, 25, Suppl., S251-S260, 1977.

Matsu'ura, M., D. D. Jackson, and A. B. Cheng, Dislocation model for aseismic crustal deformation at Hollister, California, J. Geophys. Res., 91, 12661-12674, 1986

Mogi, K., Seismicity in western Japan and long-term earthquake forecasting, in Earthquake Prediction, edited by D. W. Simpson and P. G. Richards, Maurice Ewing Series, 4, American Geophysical Union, Washington, D.C., 1981.

Okada, Y., Internal deformation due to shear and tensile faults in a halfspace, Bull. Seism. Soc. Am., 82, 1018-1040, 1992.

Peterson, E. T. and T. Seno, Factors affecting seismic moment release rates in subduction zones, J. Geophys. Res., 89, 10233-10248, 1984.

Pollitz, F. F. and I. S. Sacks, The 1995 Kobe, Japan, earthquake: A longdelayed aftershock of the offshore 1944 Tonankai and 1946 Nankaido earthquakes, Bull. Seism. Soc. Am., 87, 1-10, 1997.

Research Group for Active Faults in Japan, Active Faults in Japan, 437 pp. University of Tokyo Press, Tokyo, 1991 (in Japanese).

Ruff, L. J., Asperity distributions and large earthquake occurrence in subduction zones, Tectonophys., 211, 61-83, 1992.

Rundle, J. B., A physical model for earthquakes 1 . Fluctuations and interactions, J. Geophys. Res., 93, 6237-6254, 1988a.

Rundle, J. B., A physical model for earthquakes 2. Application to southern California, J. Geophys. Res., 93, 6255-6274, 1988b.

Rundle, J. B. and H. Kanamori, Application of an inhomogeneous stress (patch) model to complex subduction zone earthquakes: A discrete interaction matrix approach, J. Geophys. Res., 92, 2606-2616, 1987.

Savage, J. C., A dislocation model of strain accumulation and release at a subduction zone, J. Geophys. Res., 88, 4984-4996, 1982.

Schwarz, D. P. and K. J. Coppersmith, Fault behavior and characteristic earthquakes: Examples from the Wasatch and San Andreas fault zones, J. Geogphys. Res., 89, 5681-5698, 1984.

Seno, T., Pattern of intraplate seismicity in southwest Japan before and after great interplate earthquakes, Tectonophys., 57, 267-283, 1979.

Shen-Tu, B. and W. E. Holt, Interseismic deformation in northern Honshu and its relationship with the subduction of the Pacific plate in the Japan trench, Geophys. Res. Lett., 23, 3103-3106, 1996.

Shimazaki, K., Intra-plate seismicity and inter-plate earthquakes: historical activity in southwest Japan, Tectonophys., 33, 33-42, 1976.

Tsuji, Y., The Nankai earthquakes and their associated tsunamis, in "The Nankai earthquake-prepared for the next great earthquake", Chikyu (Earth Monthly), Special Issue, 24, 36-49, 1999 (in Japanese).

Utsu, T., Correlation between great earthquakes along the Nankai trough and destructive earthquakes in western Japan, Rep. Coord. Comm. Earthq. Predict., 12, 120-122, 1974a (in Japanese).

Ustu, T., Space-time pattern of large earthquakes occurring off the Pacific coast of the Japanese islands, J. Phys. Earth, 22, 325-342, 1974b.

Ward, S. N., A synthetic seismicity model for the Middle America Trench, J. Geophys. Res., 96, 21433-21442, 1991.

Ward, S. N., A synthetic seismicity model for southern California: Cycles, probabilities, and hazards, J. Geophys. Res., 101, 22393-22418, 1996.

Wesnousky, S. G., C. H. Scholz, and K. Shimazaki, Deformation of an island arc: rates of moment release and crustal shortening in intraplate Japan determined from seismicity and Quaternary fault data, J. Geophys. Res., 87, 6829-6852, 1982

Wessel, P. and W. H. F. Smith, Free software helps map and display data, EOS Trans. Amer. Geophys. U., 72, 441, 445-446, 1991.

M. Hashimoto (e-mail: hasimoto@rcep.dpri.kyoto-u.ac.jp) 